\title{
GÊNERO EM POLÍTICAS PÚBLICAS DE EDUCAÇÃO E CURRÍCULO: DO DIREITO ÀS INVENÇÕES
}

\author{
Lívia de Rezende CARDOSO ${ }^{\mathrm{i}}$ \\ Ann Letícia Aragão GUARANYii \\ Lynna Gabriella Silva UNGER ${ }^{\text {iii }}$ \\ Manuella de Aragão PIRES ${ }^{\text {iv }}$
}

\begin{abstract}
RESUMO
Nos últimos tempos, temos presenciado enunciações que materializam os efeitos da onda conservadora que paira em território nacional. A escola, nesse contexto, é campo de batalha prioritário, além de ser um dos alvos principais dos vetos e dos protestos da sociedade civil e dos representantes políticos, o que, por vezes, se materializa nas alterações das políticas públicas educacionais. É sob tal conjuntura política e sobre direitos educacionais conquistados, especificamente no que se refere à gênero nas últimas décadas, que trataremos aqui. Ao analisarmos leis, diretrizes e bases nacionais, destacamos as políticas públicas como efeitos de diferentes forças que lutam para capturar condutas, formar sujeitos e conduzir racionalidades. A partir das análises, observamos movimentos de inscrição de diversos grupos excluídos (ou expulsos) do cenário educacional, bem como o incentivo às suas promoções de modo positivo em avaliações e materiais pedagógicos. Contudo, gênero como sinônimo de sexo biológico é o conceito utilizado prioritariamente nos documentos e pouco se promove a desconstrução de normas de gênero e as invenções de outros modos de existência.
\end{abstract}

PALAVRAS-CHAVE: Políticas Públicas; Currículo; Gênero; Sexualidade; Direitos Humanos.

\section{GENDER IN EDUCATION PUBLIC POLICIES AND CURRICULUM: FROM RIGHT TO INVENTIONS}

\begin{abstract}
In recent times, we have witnessed statements that materialize the effects of the conservative wave that hovers in the national territory. The school in this context is a priority battlefield, and is one of the main targets of vetoes and protests by civil society and political representatives, which sometimes materializes in education public policies changes. It is under such a political conjuncture and about educational rights conquered, specifically with regard to gender in recent decades, that we will deal here. When analyzing national laws, guidelines and bases, we highlight the public policies as the effects of different forces that struggle to capture behavior, form subjects and lead rationalities. From these analyses, we observed movements of enrollment of several excluded (or expelled) groups from the educational scenario, as well as encouraging their promotion positively in assessments and teaching materials. However, gender as a synonym for biological sex is the concept used primarily in documents and there is little promotion of deconstruction of gender norms and inventions of others modes of existence.
\end{abstract}

KEYWORDS: Public Policies; Curriculum; Gender; Sexuality; Human rights.

\footnotetext{
${ }^{i}$ Doutora pelo Programa de Pós-Graduação em Educação, Conhecimento e Inclusão Social na Faculdade de Educação da Universidade Federal de Minas Gerais (UFMG). Professora do Programa de Pós-Graduação em Educação (PPGED) da Universidade Federal de Sergipe (UFS). E-mail: livinha.bio@ gmail.com.

${ }^{i i}$ Doutoranda no Programa de Pós-Graduação em Educação (PPGED) e Técnica em Assuntos Educacionais pela UFS. E-mail: annguarany@gmail.com.

iii Doutoranda no Programa de Pós-Graduação em Educação (PPGED) pela UFS. E-mail: E-mail: lynnaunger@gmail.com.

iv Mestranda no Programa de Pós-Graduação em Educação (PPGED) pela UFS. E-mail: manuelladearagao@yahoo.com.br. 


\title{
GÉNERO EN POLÍTICAS DE EDUCACIÓN PÚBLICA Y CURRICULUM: DEL DERECHO A LAS INVENCIONES
}

\begin{abstract}
RESUMEN
En los últimos tiempos hemos sido testigos de que las enunciaciones materializarse los efectos de la ola conservadora que se cierne en el territorio nacional. La escuela en este contexto es el campo de batalla prioritario, y es uno de los principales objetivos de los vetos y las protestas de la sociedad civil y los representantes políticos, que a veces se materializa en modificaciones de políticas públicas educativas. Es en esa coyuntura política y sobre los derechos educativos conquistada, específicamente, en relación con el género en las últimas décadas que ocuparnos aquí. Al analizar las leyes, directrices y bases nacionales, destacamos las políticas públicas como los efectos de las diferentes fuerzas que luchan por capturar comportamientos, formar sujetos y conducir racionalidades. A partir del análisis, hemos observado movimientos de inscripción de diversos grupos excluidos (o expulsados) del ambiente educativo, así como el incentivo para sus promociones de manera positiva en evaluaciones y materiales didácticos. Pero, el género como sinónimo de sexo biológico es el concepto utilizado principalmente en documentos y poco promueve la deconstrucción de las normas de género y de las invenciones de nuevos modos de existência.
\end{abstract}

PALABRAS CLAVE: Políticas públicas; Plan de estudios; Género; Sexualidad; Derechos humanos.

\section{INTRODUÇÃO}

Não se pode mais falar de gênero em sala de aula. Gênero está proibido agora na escola. Vamos ter de rever essa imagem da vulva na prova. Preciso avaliar melhor a sua pesquisa aqui na escola. Não quero problemas. Não vou inserir gênero no currículo para depois o governo tirar! Iniciamos a escrita deste artigo com recentes frases que ouvimos ao longo deste ano proferidas por sujeitos da cena educacional. Ditas nos mais diferentes contextos - em turma de formação inicial de pedagogas, em grupo de docentes em formação continuada, no Programa Residência Pedagógica de Biologia, na sala da direção da escola, quando em pesquisa de doutoramento sobre corpo e gênero, e em reunião de coordenadores de cursos em uma Instituição de Ensino Superior (IE), tais enunciações materializam os efeitos da onda conservadora que paira em território nacional.

Ao referir-se ao atual cenário político, Meyer (2018, p. 9) afirma que “[...] realizações e direitos políticos e sociais importantes, conquistados nas últimas três ou quatro décadas, têm sido subtraídos e/ou violentamente contestados”. Como define Paraíso (2018, p. 14), são tempos hostis em que “[...] assistimos a inúmeras tentativas de destituir gênero, sexualidades, feminismos, teoria queer e estudos gays e lésbicos de seu caráter científico e construcionista por acusá-los de ideologia”. A escola, nesse contexto, é campo de batalha prioritário, além de ser um dos alvos principais dos vetos e dos protestos da sociedade civil e dos representantes políticos, o que, por vezes, se materializa nas alterações das políticas públicas educacionais. 
É sob tal conjuntura política e sobre tais contestações de direitos educacionais conquistados, especificamente no que se refere à gênero nas últimas décadas, que trataremos aqui.

Como professoras, gestoras e pesquisadoras, desenvolvemos e arriscamos esta escrita coletiva, a partir do que temos nos debruçados sobre nossos objetos de pesquisas, com o intuito de mapear a cena política brasileira e as agendas de importantes políticas públicas de educação e de currículo no que se referem às questões de gênero, de sexualidade e de direitos humanos. Entendemos que "[...] currículo é território político, ético e estético incontrolável que, se é usado para regular e ordenar, pode também ser território de escapes de todos os tipos" (PARAÍSO, 2018, p. 13). Assim, considerando os múltiplos movimentos na construção de currículos escolares, ao analisarmos os documentos, destacamos as políticas públicas como efeitos de diferentes forças que lutam para capturar condutas, formar sujeitos de certos tipos e conduzir racionalidades, bem como forças propulsoras de currículos potentes que delas se inspiram.

Sem a pretensão de subscrever a escrita desta pesquisa nos manuais de verdades científicas, aqui buscaremos escapar do "impulso à verdade" (NIETZSCHE, 2007), que faz com que nos enredemos em um jogo da sedução pelo verdadeiro no qual impomos à análise aquilo que queremos ver, o que deve ser posto em questão ao se pesquisar sob lentes pós-críticas. Nessa perspectiva, trilha-se um caminho que se constrói no próprio exercício da investigação. É um caminho que aponta para uma maneira de pensar sobre a linguagem, a verdade, a subjetividade e as relações de saber-poder. É, desse modo, um pensamento criativo que busca repensar criticamente a ciência sem ter a pretensão de encerrá-la, de apresentar um método fechado (WILLIAMS, 2013). De tal modo, a orientação metodológica aqui assumida indica uma postura que rompe com a neutralidade do sujeito pesquisador em relação ao seu objeto de estudo, tendo em vista que o objeto de pesquisa é também uma produção que se dá no ato de pesquisar.

$\mathrm{Na}$ busca por compreender a historicidade das políticas públicas para Educação e Currículo no Brasil, especialmente dos anos de 1996 ao ano atual, direcionamo-nos à análise dos processos de formulação e de alteração dos documentos curriculares nacionais. O período em questão abrange desde a aprovação da Lei de Diretrizes e Bases da Educação Nacional (LDB) até as últimas bases curriculares oficiais. Contudo, para melhor compreender os fundamentos desses textos, foram incluídas referências sobre a Declaração Universal de Direitos Humanos (1948), por ter influenciado e ser citada em várias das leis e das diretrizes, e a Constituição Federal (1988), como base para nossos instrumentos legais.

Além da LDB de 1996, foram analisados outros marcos das políticas públicas em educação: Parâmetros Curriculares Nacionais (1997); Plano Nacional de Educação (2001-2011) e sua atualização, o Plano Nacional de Educação (2014-2024). Como vimos em nossas leituras e análises, a discussão dos Direitos Humanos abriu o caminho para a inclusão das diversidades, incluindo a de gênero e sexual, nas 
propostas oficiais. Por isso, foram incluídas em nosso trabalho as Diretrizes Nacionais para a Educação em Direitos Humanos - Resolução No 1, de 30 de maio de 2012; Agenda 2030 da ONU (2015) e a participação do Brasil para o atendimento de suas metas. Mais recentemente, a proposição de bases comuns para a Educação Básica e a formação docente configurou-se como campo de disputas em que a inclusão e a retirada dos termos relacionados ao gênero e à sexualidade teve protagonismo. Decorre daí a importância de serem analisadas a Base Nacional Comum Curricular (2017); as Diretrizes Curriculares Nacionais para a formação inicial em nível superior e para a formação continuada (2015); a Base Nacional Comum da Formação de Professores da Educação Básica (2018), em tramitação.

Desse modo, buscamos, tanto nos documentos em si quanto nos debates e nos pareceres que envolveram as formulações dessas políticas, os embates, as exclusões, os gritos e os silêncios que produziram e foram produzidos pelos currículos. Analisamos os conceitos de gênero que emergem desses textos, apontando as referências discursivas em torno das formas de diversidade e de diferença. Argumentamos, aqui, que existem muitos cenários discursivos, construídos em meio a relações de podersaber, competindo e se articulando para compor uma narrativa de gênero, currículo e educação brasileira nessas políticas públicas. Em tais cenários, gênero é delineado ora como extensão biológica dos corpos, como normatização de condutas, ora como possibilidade de proliferação da diferença.

\section{DA INSCRIÇÃO DE DIREITOS}

É consenso pontuar que o primeiro grande marco na análise das políticas públicas é a proclamação da Declaração Universal dos Direitos Humanos, em 1948, elaborada por representantes de todas as regiões do mundo, após a segunda guerra, na Assembleia Geral das Nações Unidas em Paris. A declaração estabelece, pela primeira vez, a proteção universal dos direitos humanos (DH) a partir da percepção do indivíduo como sujeito de direitos internacionais, o que influenciou o ordenamento jurídico de vários países, inclusive do Brasil, a partir da Constituição Federal (CF) de 1988. Conhecida como “Constituição Cidadã”, a CF dá destaque para os DH logo nas primeiras linhas do texto constitucional, demonstrando que o constituinte quis garanti-los e fazer deles a base para a nova sociedade que nascia a partir daquele documento. Já, no primeiro artigo, encontramos a dignidade da pessoa humana, os valores sociais do trabalho e da livre iniciativa e o pluralismo político como fundamentos da República (BRASIL, 1988), rompendo com a constituição anterior de 1967 (ARAÚJO; FONSECA, 2012). 
A Declaração de Direitos Humanos, como discutido por Tedeschi e Colling (2014), difere de alguns documentos anteriores que utilizam a expressão "direitos do homem", a exemplo da Declaração dos Direitos da Virginia (EUA), de 1776, e da Declaração dos Direitos do Homem e do Cidadão, de 1789, como efeito da Revolução Francesa. A declaração da Organização das Nações Unidas avança e, em todo o seu texto, fala em "direitos humanos", os quais, ainda segundo os autores, requerem três qualidades: ser naturais (inerentes aos seres humanos), iguais (os mesmos para todos) e universais (aplicáveis em toda a parte); enfatizados desde o Artigo I ao definir que "[...] todos os seres humanos nascem livres e iguais em dignidade e direitos. São dotados de razão e consciência e devem agir em relação uns aos outros com espírito de fraternidade" (ONU, 1948, p. 4). Assim como no artigo II, declara-se que "[...] todo ser humano tem capacidade para gozar os direitos e as liberdades estabelecidos nesta Declaração, sem distinção de qualquer espécie, seja de raça, cor, sexo, idioma, religião, opinião política ou de outra natureza, origem nacional ou social, riqueza, nascimento, ou qualquer outra condição" (ONU, 1948, p. 4).

Embora os "avanços" no documento sejam notórios, é válido atentar que, naquele momento, pouco se tinha de possibilidade de pensar em gênero, em um contexto social totalmente subsidiado nos referenciais biológicos para definição do ser homem ou mulher, que, por sua vez, estavam fixados na divisão binária do mundo social, em que as mulheres ainda estavam lutando pelo reconhecimento como seres humanos dotadas de capacidade para tomar decisões (SCOTT, 1995). Isso reflete na composição do documento que faz uso do termo sexo para se referir à diferenciação entre homens e mulheres. Apesar de a declaração tratar dos Direitos Humanos e utilizar "ser humano" em quase todo o texto, faz-se necessário destacar que a diferenciação dos termos homens e mulheres acontecem apenas em dois momentos.

No primeiro parágrafo do artigo XVI, está expresso: “Os homens e mulheres de maior idade, sem qualquer restrição de raça, nacionalidade ou religião, têm o direito de contrair matrimônio e fundar uma família" (ONU, 1948, p. 9). É bem no item que se refere à família que mulher e homem aparecem de forma discriminada, indicando a naturalizada relação de matrimônio, e, ainda, exclusivamente heterossexual. Esse conceito de família tradicional e natural é enfatizado e garantido no parágrafo 3 desse mesmo artigo, no qual salienta: "A família é o núcleo natural e fundamental da sociedade e tem direito à proteção da sociedade e do Estado" (ONU, 19848, p. 9). Todavia, ainda nesse item, podemos perceber que há certo avanço no que se refere ao direito do estabelecimento do matrimônio, em que casamento e dissolução são igualados na declaração, fazendo valer tal direito para homens e mulheres.

$\mathrm{O}$ contexto pós-guerra, marcado pela partida de homens para os combates, permitiu às mulheres assumirem posições antes impensadas, o que propiciou o debate por igualdade e a busca pela desnaturalização da visão de que elas seriam biologicamente inferiores, legalmente incapazes e 
politicamente dependentes. Após a Declaração Universal de Direitos Humanos de 1948, vemos a incorporação de outros conceitos nos documentos que garantem os direitos humanos, seja da ONU ou de outras organizações. Essa maior abrangência de direitos que acompanham as transformações ao longo da história são também frutos dos estudos feministas, a partir da década de 1960, e da participação feminina na política e demais esferas sociais, com a criação de comitês e emissão de recomendações específicas sobre direitos das mulheres, que discutem violência, discriminação e desigualdade de gênero (SCOTT, 1995). São processos que foram basilares para composição de novas políticas, inclusive as educacionais.

O documento que representa a importância de que educação no país fosse pautada nas bases dos DH é a Resolução No 1, de 30 de maio de 2012 (BRASIL, 2012a), que estabeleceu as Diretrizes Nacionais para a Educação em Direitos Humanos, oriunda de uma comissão interinstitucional, coordenada pelo Conselho Nacional de Educação (CNE) com participação das Secretarias de Direitos Humanos da Presidência da República (SDHPR); de Educação Continuada, Alfabetização, Diversidade e Inclusão (SECADI); de Educação Superior (SESU); de Articulação com os Sistemas de Ensino (SASE); de Educação Básica (SEB) e do Comitê Nacional de Educação em Direitos Humanos (CNEDH).

Essa Resolução foi formulada a partir do entendimento de que a educação é reconhecida como um dos DH e, por conseguinte, a Educação em DH é parte fundamental do conjunto desses direitos, direcionando aos sistemas de ensino, gestores/as, professores/as e demais profissionais da educação, a responsabilidade. Para além de assegurar a manutenção dos direitos, empenhar-se para reverter as violações destes em consequência da exclusão social, econômica, política e cultural que promovem as múltiplas formas de violências contra a pessoa humana. É importante destacarmos que, nesse contexto político, especialmente na SECADI, representantes de grupos em defesa dos DH e de organizações específicas em prol de indivíduos historicamente excluídos das decisões políticas passaram a ter espaço e constituíram a própria administração pública, participando das equipes das secretarias governamentais. Nesse sentido, as Diretrizes Nacionais para a Educação em Direitos Humanos preveem

[...] todas as pessoas, independente do seu sexo; origem nacional, étnico-racial, de suas condições econômicas, sociais ou culturais; de suas escolhas de credo; orientação sexual; identidade de gênero, faixa etária, pessoas com deficiência, altas habilidades/superdotação, transtornos globais e do desenvolvimento, têm a possibilidade de usufruírem de uma educação não discriminatória e democrática (BRASIL, 2012a, p. 2).

A Resolução № 1/2012 estabelece as diretrizes a serem adotadas pelos sistemas de ensino e suas instituições, considerando como documentos norteadores a Declaração Universal dos Direitos Humanos de 1948; a Declaração das Nações Unidas sobre a Educação e Formação em Direitos Humanos (2011); a 
Constituição Federal (1988); a Lei de Diretrizes e Bases da Educação Nacional (1996); o Programa Mundial de Educação em Direitos Humanos (PMEDH 2005/2014); o Programa Nacional de Direitos Humanos (PNDH-3/Decreto No 7.037/2009); o Plano Nacional de Educação em Direitos Humanos (PNEDH/2006); entre outras diretrizes do CNE e documentos nacionais e internacionais. A necessidade de se pensar na Educação em Direitos Humanos a partir de novas formas de organização educacional, novas metodologias de ensino e aprendizagem e atuação institucional está registrada ainda no Parecer CNE/CEP № 8, de 6 de março de 2012 (BRASIL, 2012b), que subsidiou a Resolução, justificada pelo que chamam de novo público estudantil nos ambientes educacionais, marcado pelas diversidades de grupos e sujeitos historicamente excluídos do direito à educação e dos demais direitos (BRASIL, 2012b).

No art. $3^{\circ}$ da Resolução No 1/2012 (BRASIL, 2012a, p. 2) estão colocados os princípios da Educação em DH, a saber: I - dignidade humana; II - igualdade de direitos; III - reconhecimento e valorização das diferenças e das diversidades; IV - laicidade do Estado; V - democracia na educação; VI transversalidade, vivência e globalidade; e VII - sustentabilidade socioambiental. Esses princípios deverão ser considerados na construção dos Projetos Político-Pedagógicos (PPP); dos Regimentos Escolares; dos Planos de Desenvolvimento Institucionais (PDI); dos Programas Pedagógicos de Curso (PPC) das Instituições de Educação Superior; dos materiais didáticos; do modelo de ensino, pesquisa e extensão; de gestão, bem como dos diferentes processos de avaliação, o que estabelece uma nova dinâmica na estruturação e na produção dos conhecimentos, possibilitando transformações nos ambientes educacionais de modo a efetivar uma educação socialmente mais justa, engajada e acessível para todos/as.

Cabe pontuar que os conceitos empregados na resolução estão em consonância com os documentos internacionais que versam sobre direitos humanos e incluem as diversidades e as diferenças. Esse fato nos faz compartilhar responsabilidades e metas em torno de uma política educacional cada vez mais comprometida com o bem-estar e a dignidade social. A última Agenda global da ONU para os seus 193 países-membros foi lançada no ano de seu septuagésimo aniversário, em 2015, sendo intitulada “Transformando nosso mundo: A agenda 2030 para o desenvolvimento sustentável", a ser adotada pelas respectivas nações para os 15 anos seguintes. A agenda consiste em uma Declaração com 17 Objetivos de Desenvolvimento Sustentável (ODS) e 169 metas, uma seção sobre meios de implementação e uma renovada parceria mundial, além de um mecanismo para avaliação e acompanhamento.

Os Objetivos de Desenvolvimento Sustentável (ODS) e metas a serem atendidas até 2030 no que diz respeito às dimensões econômica, social e ambiental, segundo o documento, levam em consideração as diferentes realidades nacionais e visam concretizar os direitos humanos de todos e, em particular, dos mais vulneráveis, estimulando ações para garantir a dignidade e a igualdade de todas as pessoas; proteção ao 
planeta por meio de consumo e de produção sustentável; progresso em harmonia com a natureza; promoção de sociedades pacíficas, e justas; mobilização de parcerias necessárias para a implementação da agenda (ONU, 2015). Dentre os 17 ODS, destacamos o de número 5, que propõe: "Alcançar a igualdade de gênero e empoderar todas as mulheres e meninas". A implementação das metas referentes ao ODS 5 parte de importantes avanços e conquistas sociais promovidas pelo Estado Brasileiro, porém responde a obstáculos à garantia desses direitos. São desafios: empoderamento econômico feminino; empoderamento político e representativo; a educação; a saúde; o enfrentamento da violência contra a mulher.

A despeito do estabelecimento deste ODS 5, há leis destinadas a garantir o direito específico das mulheres, a exemplo da Lei $\mathrm{N}^{\mathrm{0}}$ 11.340, de 7 de agosto de 2006 (Lei Maria da Penha), que cria mecanismos para coibir e prevenir a violência doméstica e familiar contra a mulher (BRASIL, 2006); a Lei $\mathrm{N}^{\mathrm{o}} 12.015$, de 7 de agosto de 2009, que amplia o entendimento do estupro (BRASIL, 2009); a Lei N ${ }^{\mathrm{o}}$ 13.104, de 9 de março de 2015 (Lei do Feminicídio), que prevê o feminicídio como circunstância qualificadora do crime de homicídio e como hediondo (BRASIL, 2015c); o Decreto $\mathrm{N}^{\mathrm{o}}$ 7.958, de 13 de março de 2013,que estabelece diretrizes para o atendimento humanizado às vítimas de violência sexual (BRASIL, 2013).

Avançar na garantia dos direitos reprodutivos e sexuais das mulheres com maior divulgação de informações, assistência médica, disponibilização de métodos contraceptivos é outra medida importante para a igualdade das relações de gênero. Ponto fundamental também, segundo a Agenda 2030, é a necessidade de produção de dados até então invisibilizados, já que parte significativa das estatísticas e das pesquisas oficiais não contemplam dados sobre raça/etnia interseccionados com recorte de gênero; além disso, o país não coleta informações oficiais sobre orientação sexual e identidade de gênero. Tais informações são fundamentais para enfrentar as situações de vulnerabilidade social e as desvantagens as quais essas populações estão sujeitas.

Em julho de 2018, foi lançado o Relatório Luz do Grupo de Trabalho da sociedade civil para a Agenda 2030 no Brasil. O relatório tem por objetivo monitorar a implementação dos ODS no Brasil pós 2015 até primeiro semestre de 2018. Segundo dados divulgados, o país está trilhando, nos últimos anos, um caminho contrário ao compromisso firmado nos ODS, especificamente em relação ao ODS 5. Pela estimativa relatada, o país só conseguiria alcançar uma possível igualdade de gênero em 2080. O relatório aponta a necessidade de melhorar os indicadores para implementar políticas de melhoria da coleta, publicação e divulgação de dados, além de recomendar a necessidade de assegurar a discussão de gênero e a diversidade sexual nas escolas e destinar recursos para políticas públicas de combate à violência de gênero, acesso à educação de qualidade, profissionalização e emprego digno. 
O reconhecimento dos $\mathrm{DH}$, a partir de documentos e de políticas internacionais, configurou-se como um primeiro passo nas garantias mínimas de existência, ao menos nas leis, de grupos até então invisibilizados. Nesse sentido, a Constituição Federal (1988) e as Diretrizes Educacionais para os Direitos Humanos (2012) foram influenciados pela Declaração Universal dos Direitos Humanos (1948) e pela agenda da ONU, que garantiram a inscrição da discussão de gênero - mesmo como sinônimo de sexo biológico - na agenda curricular brasileira. Vemos, a partir desse primeiro movimento de inserção homogênea, como as políticas públicas educacionais podem se constituir como "[...] trama complexa, na qual a diferença, sem a qual não há educação, é constrangida" (MACEDO; RANNIERY, 2018, p. 743).

\section{DAS MINIMIZAÇÕES}

Em 1996, foi elaborada a Lei de Diretrizes e Bases da Educação Nacional (LDB), que instituiu a política educacional brasileira (BRASIL, 1996). É, pois, a partir da aprovação dessa lei, que se delimita que a educação no Brasil deve ser organizada e administrada separadamente por cada nível de governo, decentralizando suas ações. Com base na LDB, o sistema de ensino concede às escolas públicas, entre outras incumbências, a autonomia para a elaboração da proposta pedagógica. A partir disso, outras medidas foram promulgadas e organizadas com o objetivo de orientar a educação no país. No tocante às questões de gênero e à educação para as relações de gênero e sexualidade, a LDB (BRASIL, 1996) não trouxe explicitamente normas que problematizassem as diferenças entre os papéis sociais de cada gênero.

O desenho constitucional era bastante complexo, pois, ao passo que diretrizes internacionais elaboravam políticas de restrições de direitos sociais, também ascendiam, na cultura política, movimentos de resistências e de ganhos populares. Houve, na década de 1990, uma grande e contraditória articulação entre os planos educacionais e os programas estratégicos para o desenvolvimento econômicos do país. As reformas e as elaborações de documentos nacionais orientadores da educação brasileira tomaram rumos e proporções nunca antes vistos no âmbito das políticas educacionais nacionais. Foram instituídos os Parâmetros Curriculares Nacionais (PCN) e o Plano Nacional de Educação (PNE), sendo que este último passaria a vigorar somente a partir do ano de 2001 e fora atualizado no Plano Decenal de Educação para todos (2014-2024). Os PCN configuraram-se como diretrizes federativas, intervindo diretamente nos currículos dos níveis Fundamental e Médio (BRASIL, 1998). Nesse cenário:

A abrangência, o caráter inédito e a grande visibilidade das reformas federais implantadas no final dos anos de 1990 criaram um campo de discussão envolvendo os contestadores da matriz ideológico-doutrinária do governo de Fernando Henrique Cardoso. Não cabe aqui um exame aprofundado desse caráter e de sua marca na atual LDB, no PNE e nos 
PCN [...]. A análise aqui empreendida considera marca indelével a mencionada contradição entre a forte reorientação pela ótica neoliberal e a defesa de várias conquistas de direitos sociais com base na Constituição Federal, mas enfatiza os aspectos das políticas educacionais concernentes à manutenção e/ou supressão das desigualdades de gênero (VIANNA; UNBEHAUM, 2004, p. 83).

Frigotto e Ciavatta (2003) sublinham que as análises críticas referentes ao governo de FHC apontam, em sua totalidade, para o fato de que o regime neoliberal das décadas de 1990 e 2000 direcionou as esferas políticas a articularem-se e subordinarem-se aos organismos internacionais. Esse processo também ocorreu com a educação, as políticas educacionais e, consequentemente, as políticas curriculares foram formuladas seguindo à risca a cartilha neoliberal, cujo auge pautou-se na meritocracia, na liberdade instaurada no e pelo livre mercado, na concorrência e na competitividade. Desde o campo macro das políticas públicas, passando pelas políticas educacionais até atingirem as políticas curriculares, podemos observar a lógica neoliberal fundamentando e atravessando a educação e a sociedade em todos os sentidos.

As especificidades relacionadas às questões de gênero e sexualidade situam-se como um marco histórico na implementação dos PCN em 1997, trazendo as orientações separadas por área em vários cadernos, incluindo um volume para tratar especificamente da temática da diversidade sexual. O caderno intitulado "Orientação Sexual" (volume 10.2) traz, em seu conteúdo, as questões de educação para as relações de gênero e de sexualidade. Os PCN configuraram-se um avanço nas políticas curriculares, especialmente pela elaboração desse caderno específico, organizado para que os currículos e cotidianos práticos incorporassem as pluralidades sexuais e de gênero, orientando, desse modo, uma formação escolar e humana menos machista. Tal como Nardi (2008) salienta, os PCN sugerem que a temática da orientação sexual e para as relações de gênero seja trabalhada de forma transversal em todas as disciplinas e articulada a outros temas, como ética, saúde, gênero, ecologia e pluralidade cultural.

Posteriormente, o primeiro Plano Nacional de Educação - PNE (BRASIL, 2001) foi aprovado, estabelecendo metas decenais a serem cumpridas. Para além das metas, o "Plano" instaurou a obrigatoriedade de os Estados, Distritos Federais e municípios elaborarem seus respectivos planos de educação para a década seguinte, salientando que a sociedade civil juntamente aos Estados, Distrito Federal e municípios avaliariam a implementação do PNE (BRASIL, 2001). É fato que o PNE trouxe um currículo permeado por diretrizes democráticas e lineares às demandas firmadas em torno dos DH Universais. Nessa direção, afirmam suas diretrizes gerais a garantia da organização de currículos que assegurassem a pluralidade da identidade do povo brasileiro, o desenvolvimento da cidadania, as diversidades regionais, étnicas, culturais, articulados pelo Sistema Nacional de Educação (BRASIL, 2001). Assim, deu-se o processo de incluir nos currículos temas de história, cultura, manifestações artísticas, científicas, religiosas e 
resistência da raça negra, povos indígenas e trabalhadores rurais, e suas influências e contribuições para a sociedade e a educação brasileira (VIANNA; UNBEHAUM, 2004).

O PNE (2001) pontuou explicitamente as questões ligadas à educação para as relações de gênero e direitos humanos. Dentre suas metas, a $12^{\mathrm{a}}$ meta assegurava que a União deveria:

Incluir nas diretrizes curriculares dos cursos de formação de docentes temas relacionados às problemáticas tratadas nos temas transversais, especialmente no que se refere à abordagem tais como: gênero, educação sexual, ética (justiça, diálogo, respeito mútuo, solidariedade e tolerância), pluralidade cultural, meio ambiente, saúde e temas locais (BRASIL, 2001, p. 35).

Todavia, no processo temporal de atualização do PNE, vemos alguns retrocessos ganharem espaços e tomar formas na composição das metas do atual plano decenal de Educação. A progressão dos debates sobre a educação para as relações de gênero despertaram várias críticas e ataques vindos principalmente da ala mais conservadora do Senado que, em conjunto com o grupo político que ficou popularmente conhecido como bancada da Bíblia, gerou tensionamentos e declínios na redação final do PNE (BRASIL, 2014), que seria aprovado em 2014 com vigência até 2024. Nessa direção, vemos orientações que alastram a política educacional atual, desconsiderando o histórico de disputas e conquistas, instaurando enormes retrocessos e desajustes para o campo educacional. De acordo com Reis e Eggert (2017), durante os debates de elaboração do Plano Nacional de Educação (BRASIL, 2011), assim como nas discussões em torno dos Planos Municipais e Estaduais de Educação, surgiram discursos, vindos da ala conservadora, que acusavam pensadores críticos, principalmente aqueles ligados à promoção de políticas voltadas à igualdade de gêneros, de estarem se utilizando da "ideologia de gênero". O termo ideologia de gênero surgiu no cenário brasileiro como Projeto de Lei, endossando o discurso conservador e reacionário, para os defensores da falácia denominada ideologia de gênero, em que atribuem ao "conceito" à desconstrução dos papéis tradicionais e naturais de gênero (JUNQUEIRA, 2018).

Cabe ressaltar que, nos Documentos Finais das Conferências de Educação de 2008, 2010 e 2014 ou tampouco na versão inicial do Plano Nacional de Educação (BRASIL, 2011), elaboraram-se diretrizes que referenciassem o termo "ideologia de gênero". O que aparece nos documentos, assim como já orientavam as diretrizes da ONU desde os anos de 1990, é que se objetivasse garantir a equidade entre os gêneros, sobretudo no plano educacional. Ao final do processo de formulação do novo PNE (BRASIL, 2011), o documento de caráter curricular nacional havia foi permeado por conceitos ideológicos que se pautaram na falsa premissa da "ideologia de gênero", por meio da qual se apresentava a errônea ideia de que a busca da luta por equidade de gênero traria a destruição das bases da "família tradicional brasileira". 
Esses embates merecem destaque, pois representam o cenário vivido nos últimos anos e que influem na composição das Políticas Públicas Educacionais atuais e nos respectivos documentos oficiais. Em meados de 2017, o MEC entregou a terceira versão da Base Nacional Comum Curricular (BNCC) ao Conselho Nacional da Educação (CNE). A BNCC, no entanto, chegou aos conselheiros com alterações, dentre elas foram retirados os termos "gênero" e "orientação sexual" de trechos específicos. A versão anterior, por sua vez, estabelecia como um dos objetos de conhecimento "[...] corpo, gênero e sexualidade nas tradições religiosas" e definia que as escolas deveriam "[...] discutir as distintas concepções de gênero e sexualidade segundo diferentes tradições religiosas e filosofias de vida" (BRASIL, 2016, p. 29).

Após discussões entre 22 conselheiros, apenas três votaram pela permanência. Assim, essas temáticas deixaram de compor os objetos de conhecimento do documento final. Em lugar destes, foi incluído o eixo "princípios e valores éticos", que tem como umas das habilidades "[...] reconhecer a coexistência como uma atitude ética de respeito à vida e à dignidade humana" (BRASIL, 2016, p. 459). Cabe lembrar que tais discussões e controvérsias relacionadas às temáticas gênero e orientação sexual existiam bem antes da BNCC em documentos oficiais sobre Educação no Brasil, como já destacamos ao longo do texto. Outro exemplo desses conflitos deu-se em 2011, com o projeto Escola sem Homofobia, que tinha como um dos objetivos orientar docentes sobre questões relacionadas às violações aos direitos no que tange orientações sexuais que e repercutiu como "kit gay", sendo reprovado pelo congresso.

É importante ressaltar que gênero e sexualidade são construções sociais e históricas em que os conceitos de masculinidade e feminilidade se constituem de maneiras diversas, isto é, são marcados conforme a religião, a raça, a etnia, a classe, a idade, a região (MARTINS, 2015). Logo, para que se possam discutir essas temáticas de forma crítica e fundamentada, faz-se necessário que sejam problematizados alguns de seus aspectos constitutivos; entretanto, foi pela via da exclusão que eles seguiram realizando mais alterações relacionadas às temáticas de gênero e de sexualidade nos documentos curriculares, desta vez na redação final da BNCC. Para melhor explicitar as mudanças, destacamos trechos que passaram por alterações em itálico e os termos retirados estão sublinhados.

A primeira alteração ocorreu no art. 16 da Resolução $\mathrm{N}^{\mathrm{o}}$ 7, de 14 de dezembro de 2010, responsável por fixar Diretrizes Nacionais para o Ensino Fundamental de nove anos:

Os componentes curriculares e as áreas de conhecimento devem articular em seus conteúdos, a partir das possibilidades abertas pelos seus referenciais, a abordagem de temas abrangentes e contemporâneos que afetam a vida humana em escala global, regional e local, bem como na esfera individual. Temas como saúde, sexualidade $e$ gênero, vida familiar e social, assim como os direitos das crianças e adolescentes, de acordo com o Estatuto da Criança e do Adolescente (Lei no 8.069/90), preservação do 
meio ambiente, nos termos da política nacional de educação ambiental (Lei no 9.795/99), educação para o consumo, educação fiscal, trabalho, ciência e tecnologia, e diversidade cultural devem permear o desenvolvimento dos conteúdos da base nacional comum e da parte diversificada do currículo (BRASIL, 2010, p. 5).

Em consequência, a BNCC homologada passou por alterações. Dentre elas, competências gerais e habilidades para disciplina Ciências. A competência 9 sofreu a seguinte alteração:

Exercitar a empatia, o diálogo, a resolução de conflitos e a cooperação, fazendo-se respeitar e promovendo o respeito ao outro, com acolhimento e valorização da diversidade de indivíduos e de grupos sociais, seus saberes, identidades, culturas e potencialidades, sem preconceitos de origem, etnia, gênero, orientação sexual, idade, habilidade/necessidade, convicção religiosa ou de qualquer outra natureza, reconhecendo-se como parte de uma coletividade com a qual deve se comprometer. Qualquer outra natureza, reconhecendo-se como parte de uma coletividade com a qual deve se comprometer (BRASIL, 2017, p. 10).

Já habilidades para Ciências, as alterações foram na de código (EF08CI11):

Selecionar argumentos que evidenciem as múltiplas dimensões da sexualidade humana (biológica, sociocultural, afetiva e ética) e a necessidade de respeitar, valorizar e acolher a diversidade de indivíduos, sem preconceitos baseados nas diferenças de sexo, de identidade de gênero e de orientação sexual (BRASIL, 2017, p. 349).

A importância e a preocupação em manter esses termos nos documentos devem-se aos efeitos que a ausência dessas expressões pode produzir, dentre eles, uma visão reducionista do assunto. Segundo Junqueira (2017, p. 26), corre-se o risco de "[...] promover uma restauração do estatuto da ordem sexual tradicional e reforçar as disposições relativas às normas de gênero, à heterossexualidade obrigatória e à heteronormatividade". Essas alterações acabaram repercutindo nos planos municipais e estaduais de Educação, que deveriam prever o que seria da área nos próximos dez anos.

Se algumas políticas de currículo na educação brasileira entendem seus sujeitos como discursividades biológicas, pensam seus corpos no âmbito do sexo e atuam de modo a amenizar as desigualdades entre homens e mulheres de maneira a promover igualdade, outros cenários problematizam as normas que permitem tais práticas culturais. São políticas que concebem gênero como organizadores da vida social, "[...] implicado na concepção e na construção das relações de poder" (SCOTT, 1995, p. 93). Focam nas generificações e entendem que gênero “[...] não somente funciona como uma norma, mas é parte de uma prática regulatória que produz os corpos que governa" (BUTLER, 1999, p. 153). Esse processo dar-se-ia por repetição: a performatividade "[...] é menos um ato singular e deliberado do que um nexo de poder e discurso que repete ou parodia os gestos discursivos do poder" (BUTLER, 2003, p. 316). 


\section{DAS INVENÇÕES FORMATIVAS}

Observando o momento conflituoso iniciado na última década, aumentando-se a vigilância e a tensão sobre a educação das crianças e dos/das jovens no âmbito escolar diante da tormenta da "ideologia de gênero", vemos que a formação docente não seguiu as pressões impressas na BNCC, na recente versão do PNE. Após 13 anos da última diretriz curricular para formação de professores, foi aprovada a Resolução CNE/CP N$^{\circ} 2$, de $1^{\circ}$ de julho de 2015 , que define as Diretrizes Curriculares Nacionais (DCN) para a formação inicial em nível superior (cursos de licenciatura, cursos de formação pedagógica para graduados e cursos de segunda licenciatura) e para a formação continuada (BRASIL, 2015a). Essa diretriz introduziu alguns conteúdos obrigatórios ainda não citados nos documentos anteriores ou que estavam dispersos em resoluções específicas. Assim, está previsto no $§ 2^{\circ}$ do artigo 13 da Resolução que

[...] os cursos de formação deverão garantir nos currículos conteúdos específicos da respectiva área de conhecimento ou interdisciplinares, seus fundamentos e metodologias, bem como conteúdos relacionados aos fundamentos da educação, formação na área de políticas públicas e gestão da educação, seus fundamentos e metodologias, direitos humanos, diversidades étnico-racial, de gênero, sexual, religiosa, de faixa geracional, Língua Brasileira de Sinais (Libras), educação especial e direitos educacionais de adolescentes e jovens em cumprimento de medidas socioeducativas. (BRASIL, 2015a, p. 12).

A DCN anterior, aprovada por meio da Resolução CNE/CP N ${ }^{0}$, de 18 de fevereiro de 2002, tratava os conhecimentos exigidos nos cursos de formação de forma mais generalista e técnica, indicando que deveriam garantir a formação específica relacionada às diferentes etapas da Educação Básica e propiciar a inserção no debate de questões culturais, sociais, econômicas e o conhecimento sobre desenvolvimento humano e docência. Não foram mencionados, no texto do documento, os DH nem qualquer tipo de diversidade. O termo humano é utilizado sem distinção ou qualquer marca de diferença. Dessa forma, a mais recente Resolução apresenta avanços que estão expressos no próprio Parecer que a subsidiou, no qual se afirma a intenção de que tais diretrizes devam fazer repensar a Educação Básica e suas políticas para que sejam pautadas na diversidade, direitos humanos e inclusão, reconhecendo a escola como espaço de construção identitária, respeitando e valorizando as diferenças (BRASIL, 2015b).

Ressalta, ainda, a necessidade de que o processo formativo exija a liberdade e a pluralidade, por meio do reconhecimento e da valorização das diferenças nas suas diversas dimensões, em especial à 
diversidade étnico-racial, sexual, de gênero e identidade de gênero, geracional, cultural e regional como princípios de equidade, além das diferenças cognitivas e físicas, não devendo se limitar ao respeito e à tolerância, mas como parte do processo formativo que deve impactar o currículo, a prática pedagógica e a gestão escolar. No art. $8^{\circ}$ da Resolução, estão definidas as aptidões dos egressos dos cursos de licenciatura, das quais destacamos os incisos VII, que prevê que o professor deve conseguir identificar questões e problemas socioculturais e educacionais visando contribuir para a superação de exclusões sociais, étnicoraciais, econômicas, culturais, religiosas, políticas, de gênero, sexuais e outras em realidades complexas. Nessa direção, há também o inciso VIII que define a necessidade de o professor ter consciência da diversidade, respeitando as diferenças de qualquer natureza, inclusive de gêneros e sexual.

Essa resolução, que até o momento ainda está em vigor e deve ser considerada para pautar a formação docente, inaugura algumas possibilidades até então não conhecidas nas normativas educacionais no que se referem às questões de gênero. Se presenciamos, nas duas últimas décadas do século XX, a política educacional brasileira inscrever novos grupos nos direitos à educação e, na primeira década do século XXI, a tentativa de minimização das desigualdades de gênero, tal documento da diretriz recomenda a invenção de práticas formativas. Ao estimular a inserção de conteúdos sobre gênero, o emprego da escola como espaço de construção identitária, a superação de processos de exclusão pela dimensão da diversidade e a valorização das diferenças, essa política curricular rompe a tradição de limitar-se ao ensino da tolerância e passa ao desejo de proliferação da diferença. Diferença que é o motor da vida (PARAÍSO, 2015).

Para Silva (2011, p. 100), “[...] antes de tolerar, respeitar e admitir a diferença, é preciso explicar como ela é ativamente produzida"; desse modo, as identidades e as diferenças não estão dadas e convivendo harmoniosamente, mas são construídas socialmente em meio a disputas de relações de poder, que hierarquizam e instituem normalidades. Há, nas políticas públicas, uma invocação benevolente à tolerância cuja intenção é fixar identidades, homogeneizar e abrandar as lutas por representação em um contexto neoliberal. Tolerar parte da naturalização de um ponto central considerado padrão de onde os diversos partem e são constituídos como "outros" a serem aceitos e incorporados em uma racionalidade universal, que "respeita" suas particularidades sem ser questionada. Rodrigues e Abramowicz (2013) entendem isso como estratégia política de apaziguamento das diferenças e das desigualdades. As autoras discutem como o reconhecimento das várias identidades e/ou culturas, atravessado pela questão da tolerância, significa manter intactas as hierarquias do que é considerado hegemônico.

O prazo estabelecido pela Diretriz de Formação foi adiado por duas vezes até o atual prazo, justificado pela necessidade de adequação à Base Nacional Comum Curricular (BNCC), naquele momento ainda não aprovada em totalidade. A alegação que fundamentou a decisão do Conselho traz preocupação, 
pois a versão aprovada da BNCC para o Ensino Fundamental mostrou-nos que gênero foi alvo de protesto de grupos conservadores. Após a implementação da BNCC para a Educação Básica, emergiu, segundo o MEC, a necessidade de colocar-se em debate a formação inicial e continuada de professores da Educação Básica, em atendimento ao que consta no texto da Resolução CNE/CP N 2 , de 22 de dezembro de 2017, especificamente no art. 17, que diz:

Na perspectiva de valorização do professor e da sua formação inicial e continuada, as normas, os currículos dos cursos e programas a eles destinados devem adequar-se à $\mathrm{BNCC}$, nos termos do $\S 8^{\circ}$ do art.61 da LDB, devendo ser implementados no prazo de dois anos, contados da publicação da BNCC, de acordo com o art.11 da Lei 13.415/2017 (BRASIL, 2017, p. 11).

Diante disso, o MEC elaborou uma proposta para a Base Nacional Comum da Formação de Professores da Educação Básica (BNC) para apreciação do CNE, com o objetivo de iniciar debates e, após essa etapa, o documento seguir para homologação, adquirindo um caráter normativo. Pretende-se com o estabelecimento dessa BNC orientar todas as formas de habilitação para a docência nas etapas e nas modalidades da Educação Infantil, do Fundamental e do Médio e, ainda, "[...] orientar a atualização que for necessária das Diretrizes Curriculares Nacionais já editadas pelo CNE para a formação inicial e continuada dos professores da Educação Básica" (BRASIL, 2018, p. 9). A necessidade de tal documento foi justificada pelo que a proposta chama de "evidências" surgidas a partir dos resultados de pesquisas e de estudos nacionais que apontam o mau desempenho dos alunos no Ensino Fundamental e no Ensino Médio, bem como por pesquisas internacionais, que consentem na ideia de que "[...] a qualidade dos professores é a alavanca mais importante para melhorar os resultados dos alunos” (BRASIL, 2018, p. 6).

Com relação ao possível tratamento das questões de diversidade de gênero ou diversidade sexual, a única menção que o documento traz, de forma genérica, aparece nas competências profissionais da dimensão "engajamento profissional”, a saber:

3.2.2 Conhecer, entender e dar valor positivo às diferentes identidades dos estudantes brasileiros e ser capaz de utilizar a diversidade como recurso pedagógico para garantir as aprendizagens dos objetos de conhecimento; 3.2.3 Atentar e identificar formas de violência e discriminação nas escolas (BRASIL, 2018, p. 55).

O tratamento superficial de questões acerca da diversidade e da educação para relações de gênero pelo documento não surpreende, já que ele foi construído tendo como referência a BNCC, a qual também trata de camuflar tais temáticas. Isso reforça os passos largos que estamos a vivenciar na conjuntura atual rumo ao desmoronamento das conquistas outrora sedimentadas nos documentos educacionais, ao passo que evidencia que não existe uma real 
preocupação em compreender e romper com as violações e as discriminações de gênero, étnicoracial, de identidades sexuais, dentre outras marcas de vulnerabilidade social. Em contrapartida, tal desmonte de direitos não são implementados sem resistências.

\section{PARA CONTINUAR EM MOVIMENTO}

A distorção das bases da educação para as relações de gênero, além de pouco sólidas, não condizem verdadeiramente com os propósitos dos pensadores de políticas educacionais voltadas à promoção da equidade de gênero. Tal como destacam Reis e Eggert (2017, p. 19), o que se pretendia com a promoção da igualdade de gênero e de orientação sexual era contribuir para "[...] a superação das desigualdades educacionais que comprovadamente existem entre os gêneros, em consonância com as décadas de debates, acordos e políticas públicas estabelecidos democraticamente a fim de promover a equidade de gênero". Além disso, por vezes, gênero manifestou-se dentro dos DH - por supor que seria intrínseco ao termo - e da cidadania. Em outras, gênero relacionou-se apenas à mulher ou às dimensões da reprodução. Gênero não foi operado nos documentos analisados como uma categoria que desestabiliza normas, que aponta as construções hegemônicas e que extrapola os destinos biológico e cultural.

As políticas públicas brasileiras trazem claramente as marcas das relações de poder estabelecidas entre os discursos que circulam e se fortalecem em cada momento político e social vivido. Com a pesquisa que embasou este artigo, observamos um esforço na construção de normativas, de parâmetros e de diretrizes desde o final do século $\mathrm{XX}$, que promovessem a inserção e a educação para a tolerância aos grupos minoritários, até então demasiadamente excluídos (ou expulsos) do cenário educacional. Trata-se de uma tentativa de inscrição desses diversos grupos no direito ao acesso e à permanência na educação. Pudemos perceber o surgimento, ao menos institucional na elaboração de políticas, da discussão dos Direitos Humanos e das relações de gênero e sexuais na educação brasileira.

O segundo movimento das políticas educacionais foi pautado pelo intuito de minimizar as desigualdades a partir de marcadores culturais. Aí, empreenderam-se esforços em promover positivamente a existência de mulheres, negros e indígenas em materiais, currículos, conteúdos e práticas escolares. Contudo, pouco se problematizaram as matrizes discursivas de produção das desigualdades entre grupos, sejam de classe, de gênero, de sexo ou de etnia. Não cumprimos nossa função de educar pela desconstrução do desejo por poder e dominação, características que 
pautam a vida fascista em nossas condutas cotidianas (FOUCAULT, 2005). Enfraquecidos, abrimos possibilidades de intervenção da onda conservadora em nossas políticas ainda tão frágeis, produzindo-se um movimento de retrocessos nas mais recentes normativas.

Esses três movimentos, não como estágios estanques, mas como tendências propiciadas pelas condições históricas e políticas, deixaram marcas na elaboração das políticas públicas apresentadas. Entretanto, a identificação das repercussões dessas políticas na educação formal brasileira se mostrou como carente de dados, embora as reações, tanto em defesa quanto contra esses documentos, possam sinalizar os contrastes de como essas políticas são "absorvidas" pelos profissionais da educação nas instituições de ensino. Cabe ressaltar que, apesar do esforço em instrumentalizar as políticas, não se percebe o mesmo empenho em oferecer as condições de materialização das recomendações e na avaliação do atendimento ao que foi proposto.

Chegamos ao final desta escrita com aflitos anseios de prevermos o que nos espera nos próximos cenários curriculares. Contudo, lembramos que "[...] se nos apegamos somente àquilo que podemos prever e garantir, se buscamos um começo, um fundamento, temos uma falsa sensação de movimento" (ANJOS; CARDOSO, 2014, p. 77). Então, é tempo de continuarmos o movimento, de intensificarmos os embates, de somarmos àqueles e àquelas que compartilham o desejo de estranhar o que nos impõem. Como nos sentencia Paraíso (2018, p. 19), “[...] somos muitos/as, somos mais a cada dia, somos multidões. Nós, multidões, estamos grávidos/as de necessidades de exercitar nossas liberdades, de nos unir, de resistir, de fazer a diferença".

\section{REFERÊNCIAS}

ANJOS, Juliana. P.; CARDOSO, Lívia de R. Hanami ou corpos fogem, vazam, escapam... Revista Tempos e Espaços em Educação, São Cristóvão, v. 7, p. 69-78, 2014.

ARAÚJO, Luis Felipe; FONSECA, Charlie Rodrigues. A influência da Declaração Universal dos Direitos Humanos no Direito brasileiro. Revista Jus Navigandi, Teresina, ano 17, n. 3200, 5 abr. 2012. Disponível em: https://jus.com.br/artigos/21440. Acesso em: 10 dez. 2019.

BRASIL. [Constituição (1988)]. Constituição da República Federativa do Brasil. Brasília, DF: Senado, 1988.

BRASIL. Lei No 9.394, de 20 de dezembro de 1996. Estabelece as diretrizes e bases da educação nacional. Diário Oficial da União: seção 1, Brasília, DF, n. 248, p. 27833-27841, 23 dez. 1996. 
BRASIL. Ministério da Educação e do Desporto. Secretaria de Educação Fundamental. Parâmetros Curriculares Nacionais terceiro e quarto ciclos do ensino fundamental: Introdução aos parâmetros curriculares nacionais. Brasília, DF: MEC/SEF, 1998.

BRASIL. Lei No 10.172, de 9 de janeiro de 2001. Aprova o Plano Nacional de Educação e dá outras providências. Diário Oficial da União: seção 1, Brasília, DF, n. 7, p.1-20, 10 jan.2001.

BRASIL. Lei $\mathbf{N}^{\mathbf{0}}$ 11.340, de 7 de agosto de 2006. Cria mecanismos para coibir a violência doméstica e familiar contra a mulher, nos termos do $\S 8^{\circ}$ do art. 226 da Constituição Federal, da Convenção sobre a Eliminação de Todas as Formas de Discriminação contra as Mulheres e da Convenção Interamericana para Prevenir, Punir e Erradicar a Violência contra a Mulher; dispõe sobre a criação dos Juizados de Violência Doméstica e Familiar contra a Mulher; altera o Código de Processo Penal, o Código Penal e a Lei de Execução Penal; e dá outras providências. Brasília: Presidência da República, Casa Civil, Subchefia para Assuntos Jurídicos, [2006]. Disponível em: http://www.planalto.gov.br/ccivil_03/_ato2004-2006/2006/lei/111340.htm. Acesso em: 10 dez. 2019.

BRASIL. Lei $\mathbf{N}^{\mathbf{0}}$ 12.015, de 7 de agosto de 2009. Altera o Título VI da Parte Especial do DecretoLei $\mathrm{n}^{\mathrm{o}}$ 2.848, de 7 de dezembro de 1940 - Código Penal, e o art. $1^{\circ}$ da Lei $\mathrm{n}^{\mathrm{o}}$ 8.072, de 25 de julho de 1990, que dispõe sobre os crimes hediondos, nos termos do inciso XLIII do art. $5^{\circ}$ da Constituição Federal e revoga a Lei $n^{0} 2.252$, de $1^{0}$ de julho de 1954 , que trata de corrupção de menores. Brasília: Presidência da República, Casa Civil, Subchefia para Assuntos Jurídicos, [2009]. Disponível em: http://www.planalto.gov.br/ccivil_03/_Ato20072010/2009/Lei/L12015.htm. Acesso em: 10 dez. 2019.

BRASIL. Resolução $\mathbf{N}^{\mathbf{0}}$ 7, de 14 de dezembro de 2010. Fixa Diretrizes Curriculares Nacionais para o Ensino Fundamental de 9 (nove) anos. Brasília: Ministério da Educação, Conselho Nacional de Educação, Câmara de Educação Básica, [2010]. Disponível em:

http://portal.mec.gov.br/dmdocuments/rceb007_10.pdf. Acesso em: 10 dez. 2019.

BRASIL. Câmara dos Deputados. Centro de Documentação e Informação. Projeto de Lei do Plano Nacional de Educação (PNE - 2011/2020). Brasília: Biblioteca Digital, Câmara dos Deputados, 2011. Disponível em: http://bd.camara.gov.br/bd/bitstream/handle/bdcamara/5826/projeto_pne_2011_2020.pdf?sequence=1. Acesso em: 10 dez. 2019.

BRASIL. Resolução CNE/CP Nº 1, de 30 de maio de 2012. Diretrizes Nacionais para a Educação em Direitos Humanos. Magistério da Educação Básica. Brasília: Ministério da Educação, Conselho Nacional de Educação, Conselho Pleno, [2012a]. Disponível em: http://portal.mec.gov.br/dmdocuments/rcp001_12.pdf. Acesso em: 10 dez. 2019.

BRASIL. Parecer CNE/CEP N ${ }^{\circ}$, de 6 de março de 2012. Estabelece as Diretrizes Nacionais para a Educação em Direitos Humanos. Magistério da Educação Básica. Brasília: Ministério da Educação, Conselho Nacional de Educação, [2012b]. Disponível em: http://portal.mec.gov.br/index.php?option=com_docman\&view=download\&alias=10356pceb008-12-pdf\&Itemid=30192. Acesso em: 10 dez. 2019.

BRASIL. Decreto $\mathbf{N}^{\mathbf{0}}$ 7.958, de 13 de março de 2013. Estabelece diretrizes para o atendimento às vítimas de violência sexual pelos profissionais de segurança pública e da rede de atendimento do 
Sistema Único de Saúde. Brasília: Presidência da República, Casa Civil, Subchefia para Assuntos Jurídicos, [2013]. Disponível em: http://www.planalto.gov.br/ccivil_03/_ato20112014/2013/decreto/d7958.htm. Acesso em: $10 \mathrm{dez} .2019$.

BRASIL. Ministério da Educação. Secretaria de Articulação com os Sistemas de Ensino (MEC/ SASE). Plano Nacional da Educação: Planejando a Próxima Década Conhecendo as 20 Metas do Plano Nacional de Educação. Brasília, 2014. Disponível em: http://pne.mec.gov.br/images/pdf/pne_conhecendo_20_metas.pdf. Acesso em: 13 jul. 2019.

BRASIL. Resolução CNE/CEP N 2, de $1^{\circ}$ de julho de 2015. Define as Diretrizes Curriculares Nacionais para a formação inicial em nível superior (cursos de licenciatura, cursos de formação pedagógica para graduados e cursos de segunda licenciatura) e para a formação continuada. Brasília: Ministério da Educação, Conselho Nacional de Educação, Conselho Pleno, [2015a]. Disponível em: http://portal.mec.gov.br/docman/agosto-2017-pdf/70431-res-cne-cp-002-03072015-pdf/file. Acesso em: 10 dez. 2019.

BRASIL. Parecer $\mathrm{N}^{\mathrm{o}}$ 2, de 9 de junho de 2015. Diretrizes Curriculares Nacionais para a Formação Inicial e Continuada dos Profissionais do Magistério da Educação Básica. Diário Oficial da União: seção 1, Brasília, DF, n. 119, p. 13, 25 jun. 2015 b.

BRASIL. Lei $\mathbf{N}^{\mathbf{0}} \mathbf{1 3 . 1 0 4}$, de 9 de março de 2015. Altera o art. 121 do Decreto-Lei $\mathrm{n}^{\mathbf{o}} 2.848$, de 7 de dezembro de 1940 - Código Penal, para prever o feminicídio como circunstância qualificadora do crime de homicídio, e o art. $1^{\circ}$ da Lei $\mathrm{n}^{\circ}$ 8.072, de 25 de julho de 1990, para incluir o feminicídio no rol dos crimes hediondos. Brasília: Presidência da República, Casa Civil, Subchefia para Assuntos Jurídicos, [2015c]. Disponível em:

http://www.planalto.gov.br/ccivil_03/_Ato2015-2018/2015/Lei/L13104.htm. Acesso em: 10 dez. 2019.

BRASIL. Base Nacional Comum Curricular (BNCC). Segunda versão revista. Brasília: MEC/CONSED/UNDIME, 2016.

BRASIL. Resolução CNE/CP No 2, de 22 de dezembro de 2017. Institui e orienta a implantação da Base Nacional Comum Curricular, a ser respeitada obrigatoriamente ao longo das etapas e respectivas modalidades no âmbito da Educação Básica. Brasília: Ministério da Educação, Conselho Nacional de Educação, Conselho Pleno, [2017]. Disponível em: http://basenacionalcomum.mec.gov.br/images/historico/RESOLUCAOCNE_CP222DEDEZEM BRODE2017.pdf. Acesso em: 10 dez. 2019.

BRASIL. Ministério da Educação. Proposta para Base Nacional Comum da Formação de Professores da Educação Básica (versão preliminar). 2018. Disponível em: http://portal.mec.gov.br/index.php?option=com docman\&view=download\&alias=105091-bnc-formacaode-professores-v0\&category_slug=dezembro-2018-pdf\&Itemid=30192. Acesso em: $10 \mathrm{dez} .2019$.

BUTLER, Judith. Corpos que pesam: sobre os limites discursivos do "sexo". In: LOURO, Guacira. (Org.). O corpo educado: pedagogias da sexualidade. Belo Horizonte: Autêntica, 1999. p. 151-172. 
BUTLER, Judith. Problemas de gênero: feminismo e subversão da identidade. Rio de Janeiro: civilização Brasileira, 2003.

FOUCAULT, Michel. Arqueologia das ciências e história dos sistemas de pensamento. Ditos e Escritos II. Organizado por Manoel Barros da Motta. Rio de Janeiro: Forense Universitária, 2005.

FRIGOTTO, Gaudêncio; CIAVATTA, Maria. Educação básica no Brasil na década de 1990:

subordinação ativa e consentida à lógica do mercado. Educação \& Sociedade, Campinas, v. 24, p. 93-130, 2003.

HENRIQUES, Ricardo; FRANCO, Cláudia Tereza Signori; TELES, Jorge Luiz. (orgs.). Educação na diversidade: como indicar as diferenças?. Brasília: Secretaria de Educação Continuada, Alfabetização e Diversidade, 2006. Disponível em: http://unesdoc.unesco.org/images/0015/001545/154578por.pdf. Acesso em: 10 out. 2018.

JUNQUEIRA, Rogério Diniz. "Ideologia de Gênero": Um dispositivo retórico de uma ofensiva antifeminista. In: DIAS, Alfrancio F.; SANTOS, Elza F.; CRUZ, Maria Helena Santana (Orgs.). Gênero e sexualidades: entre invenções e desarticulações. Aracaju: Editora IFS, 2017. p. 47-61.

JUNQUEIRA, Rogério Diniz. A invenção da "ideologia de gênero": a emergência de um cenário políticodiscursivo e a elaboração de uma retórica reacionária antigênero. Psicologia e Política, São Paulo, v. 18, n. 43, p. 449-502, dez. 2018.

MACEDO, Elisabeth; RANNIERY, Thiago. Políticas Públicas de Currículo: diferença e a ideia de público. Currículo sem Fronteiras, v. 18, n. 3, p. 739-759, set./dez. 2018.

MARTINS, Luísa. Pelo menos oito Estados retiram referências a gênero dos planos de educação. GaúchaZH, 29 jun. 2015. Disponível em: http://zh.clicrbs.com.br/rs/vida-eestilo/educacao/noticia/2015/06/pelo-menos-oito-estados-retiram-referencias-a-genero-dos-planos-deeducacao-4791753.html. Acesso em: 9 ago. 2019.

MEYER, Dagmar. Prefácio. In: PARAÍSO, Marlucy Alves; CALDEIRA, Maria Carolina da Silva (Orgs.). Pesquisas sobre currículos, gênero e sexualidades. Belo Horizonte: Mazza, 2018. p. 9-11.

NARDI, Henrique Caetano. O estatuto da diversidade sexual nas políticas de educação no Brasil e na França: a comparação como ferramenta de desnaturalização do cotidiano de pesquisa. Psicologia \& Sociedade, São Paulo, v. 20, n. esp., p. 12-23, 2008.

NIETZSCHE, Friedrich. Sobre verdade e mentira no sentido extra-moral. São Paulo: Hedra, 2007.

ONU. Organização das Nações Unidas. Declaração Universal dos Direitos Humanos. Assembleia Geral das Nações Unidas em Paris. 10 dez. 1948. Disponível em:

https://nacoesunidas.org/direitoshumanos/declaracao/. Acesso em: 5 ago. 2019.

ONU. Organização das Nações Unidas. Transformando Nosso Mundo: A Agenda 2030 para o

Desenvolvimento Sustentável. 2015. Disponível em: https://nacoesunidas.org/wp-

content/uploads/2015/10/agenda2030-pt-br.pdf . Acesso em: 5. ago. 2019. 
PARAÍSO, Marlucy. Fazer do caos uma estrela dançarina no currículo: invenção política com gênero e sexualidade em tempos do slogan "ideologia de gênero". In: PARAÍSO, Marlucy; CALDEIRA, Maria C. (Orgs.). Pesquisas sobre currículos, gênero e sexualidades. Belo Horizonte: Mazza, 2018. p. 23-52.

PARAÍSO, Marlucy Alves. Um currículo entre formas e forças. Revista Educação, Porto Alegre, v. 38, n. 1, p. 49-58, jan./abr. 2015.

REIS, Toni; EGGERT, Edla. Ideologia de gênero: uma falácia construída sobre os planos de educação brasileiros. Educação e Sociedade, Campinas, v. 38, n. 138, p. 9-26, jan. 2017.

RODRIGUES, Tatiane Cosentino; ABRAMOWICZ, Anete. O debate contemporâneo sobre a diversidade e a diferença nas políticas e pesquisas em educação. Revista Educação e Pesquisa, São Paulo, v. 39, n. 1, p. 15-30, jan./mar. 2013.

SCOTT, Joan. Gênero: uma categoria útil de análise histórica. Educação \& Realidade, Porto Alegre, v. 2, n. 20, p. 71-99, jul./dez. 1995.

SILVA, Tomaz Tadeu da (Org.). Identidade e Diferença: a perspectiva dos Estudos Culturais. 10. ed. Petrópolis, RJ: Vozes, 2011.

TEDESCHI, Losandro Antonio; COLLING, Ana Maria. Os Direitos Humanos e as questões de Gênero. História Revista, Goiânia, v. 19, n. 3, p. 33-54, 2014.

VIANNA, Cláudia. Gênero, sexualidade e políticas públicas de educação: um diálogo com a produção acadêmica. Pro-Posições, Campinas, v. 23, n. 2, p. 127-143, ago. 2012.

VIANNA, Cláudia Pereira; UNBEHAUM, Sandra. O gênero nas políticas públicas de educação no Brasil: 1988-2002. Cadernos de Pesquisa, São Paulo, v. 34, n. 121, p. 77-104, 2004.

WILLIAMS, James. Pós-Estruturalismo. 2. ed. Petrópolis: Vozes, 2013.

Enviado em: 30/08/2019

Aprovado em: 03/12/2019 